25 Hindfelt B, Nilsson O. Brain infarctions in voung adults. Acta Neurol Scand $1977 ; 55: 145-57$.

26 Grindal $A B$, Cohen RJ, Saul RF, Taylor JR. Cerebral infarction in young adults. Stroke 1978;9:39-41.

27 Hitton-Jones D, Warlow CP. The causes of stroke in the young. 7 Neurol \begin{tabular}{l}
$1985 ; 2: 137-43$ \\
\hline
\end{tabular}

28 Kunitz SC, Gross CR, Heyman A, et al. The pilot stroke data bank: definition, design and data. Stroke 1984;15:740-6.

29 Anonymous. Guidelines for the treatment of hypertension. Memorandum from a WHO/ISH meeting. Lancet 1983;i:457-8.

30 Walter SD. Calculation of attributable risks from epidemiological data. Int $\mathcal{f}$ Epidemiol 1978;7:175-82.

31 Whisnant JP. The decline of stroke. Stroke 1984;15:160-8.
32 Schoenberg BS, Schoenberg DG, Pritchard DA, Lilienfeld AM, W'hisnant JP. Proportion of ischaemic stroke attributable to various forms of cardioProport of ischacmic stroke attributable to various forms of cardio1985:232 (suppl):98.

EW. Occurrence of stroke in biopsy proven temporal arteritis. Stroke 1986;17:131.

34 Henrich J, Sandercock PAG, Warkow CP. Stroke' and migraine in the Oxfordshire community stroke project. I Neurol 1986;233:257-62.

35 Anonymous. Consensus conference: treatment of stroke. Br Med $\mathcal{F}$ 1988;297: 126-8.

\title{
Randomised controlled trial of interferon alfa (lymphoblastoid interferon) in chronic non-A non-B hepatitis
}

\author{
M R Jacyna, M G Brooks, R H T Loke, J Main, I M Murray-Lyon, H C Thomas
}

\begin{abstract}
Objective-To determine the effect of low dose interferon alfa (human lymphoblastoid interferon) on aminotransferase activities in chronic non- $A$ non-B hepatitis.

Design-Prospective randomised controlled parallel group study of active treatment versus no treatment carried out over 16 weeks and preceded by baseline measurements at weeks 8 and 4 and time zero.
\end{abstract}

Setting-Hepatology outpatient clinics in secondary referral centres.

Patients-Fourteen adults with histologically proved chronic hepatitis and persistently raised aminotransferase activities for six months or more.

Interventions-Seven patients randomised to receive interferon alfa 5 megaunits (MU) daily for one week, reducing to $5 \mathrm{MU}$ thrice weekly for seven weeks, then $3 \mathrm{MU}$ thrice weekly for eight weeks. Controls not treated.

End point-Control of hepatic enzyme activity in chronic non-A non-B hepatitis.

Measurements and main results -Serum aspartate aminotransferase activity remained raised in controls (mean increase in study period $23.4 \mathrm{U} / \mathrm{l}$ ) but fell rapidly to normal in the treated group (mean decrease $106.4 \mathrm{U} / \mathrm{l}$ ). In four cases values were normal by eight weeks and in five cases by 16 weeks. Only minor side effects were recorded (fever, myalgia), which became less common as treatment progressed.

Conclusions - Continuous low dose interferon alfa reduces aspartate aminotransferase activity to normal in most patients with chronic non-A non-B

Department of Medicine,

St Mary's Hospital Medical

School, Paddington,

London W2

M R Jacyna, MD, lecturer

M G Brooks, MRCP, senior

registrar

J Main, MRCP, senior registrar

H C Thomas, FRCP, professor

Gastroenterology Unit,

Charing Cross Hospital,

London W6 8RF

R H T Loke, MRCP, research

fellow

I M Murray-Lyon, FRCP,

consultant physician

Correspondence to:

Dr Jacyna.

Br.Med f 1989;298:80-2 $\mathrm{B}$ infection, ${ }^{+}$and there have been two pilot studies of its use in chronic non-A non-B hepatitis. ${ }^{56}$ In the first study eight out of 10 treated patients had return of their serum aminotransferase activities to normal during treatment, and in the second study all three treated patients had a similar complete biochemical remission during treatment. Neither study was controlled.

These preliminary results are encouraging, but as wide fluctuations in serum aminotransferase activities occur in chronic non-A non-B hepatitis, ${ }^{7}$ controlled studies are essential. This study aimed at assessing the effect of low dose interferon alfa on aminotransferase activities in a randomised controlled study of patients with established chronic non-A non-B hepatitis.

\section{Patients and methods}

The study was an open randomised controlled parallel group study of interferon versus no treatment in patients with chronic non-A non-B hepatitis. Fourteen patients with the disease recruited from a hepatology clinic were randomised (sealed envelopes) on entry to the study. The table gives their details. All except two patients had a history of parenteral exposure to blood or blood products and the subsequent development of chronic hepatitis with persistently raised serum aminotransferase activities and liver biopsy appearances compatible with chronic non-A non-B hepatitis. All were negative for hepatitis B surface antigen, but one treated patient (case 3) had IgG core antibodies indicating previous exposure to hepatitis B. Other causes of chronic hepatitis were excluded by finding normal serum $\alpha_{1}$ antitrypsin, iron, transferrin, caeruloplasmin, and copper concentrations. No patient had antinuclear or mitochondrial antibodies, but several patients had low titres $(<1 / 40)$ of smooth muscle antibody. Alcohol and drug induced liver disease were also excluded after careful questioning. All patients were negative for antibody to human immunodeficiency virus (HIV) at entry to the study, but one treated patient (case 5) seroconverted to HIV shortly after starting interferon. Patients gave informed consent and the study was approved by the local ethical committees.

Treatment was with interferon alfa (Wellferon). The interferon was given by intramuscular or deep subcutaneous injection and the patients taught to self inject. The dosage was 5 megaunits (MU) daily for the first week, reducing to $5 \mathrm{MU}$ thrice weekly for seven weeks, then $3 \mathrm{MU}$ thrice weekly after this time if aminotransferase activities were normal. If aminotransferase activities were not normal by this time then the patients continued with $5 \mathrm{MU}$ thrice weekly. Most patients developed a transient fever and myalgia within a few hours of the interferon and were advised to take paracetamol ( $500 \mathrm{mg}$ every six hours) if required. Patients were seen at weekly intervals for the first month and then monthly. At each visit patients were questioned about possible side effects and a full 
reduction between time zero and 16 weeks $106 \cdot 4 \mathrm{U} / \mathrm{l}$ ) was sustained over the period of treatment. In the control group no patient showed any consistent change in aspartate aminotransferase activity during the same time period, and the mean activity increased slightly between time zero and 16 weeks (mean increase $23.4 \mathrm{U} / \mathrm{l})$. For each patient the four post-treatment values were subtracted from the mean of the three pretreatment values. Analysis of variance for repeated measures showed a pronounced treatment effect $\left(F_{1,12}=31.95 ; p<0.001\right)$ and no interactions between treatment and time. Though all the treated patients showed an initial fall in aspartate aminotransferase activity, two (cases 6 and 7) still had abnormal activities by 16 weeks; in one of these patients early cirrhosis was found on liver biopsy.

The treatment was well tolerated by all patients, the main side effects being fever, chills, and myalgia for a few hours after the initial interferon injections. These side effects became less common after several weeks of treatment, and most patients had minimal or no side effects when the interferon was reduced to $3 \mathrm{MU}$ thrice weekly. One patient reported mild hair loss and depression. Five of the treated patients (whose aspartate aminotransferase activities returned to normal) reported feeling better and less fatigued. Symptoms in the remaining two patients remained unchanged.

The figure shows the aspartate aminotransferase activities of patients in the treated and control groups. Analysis of variance for repeated measures showed that there was no significant difference in the pretreatment activities of the enzyme between the two groups. After the start of interferon, however, there was a rapid fall in aspartate aminotransferase activity towards normal in all treated patients, which continued throughout the period of treatment. In three treated patients activities were in the normal range by four weeks, in four by eight weeks, and five of the treated patients had entirely normal aspartate aminotransferase activities by 16 weeks. This reduction in aspartate aminotransferase activities in the treated group (mean

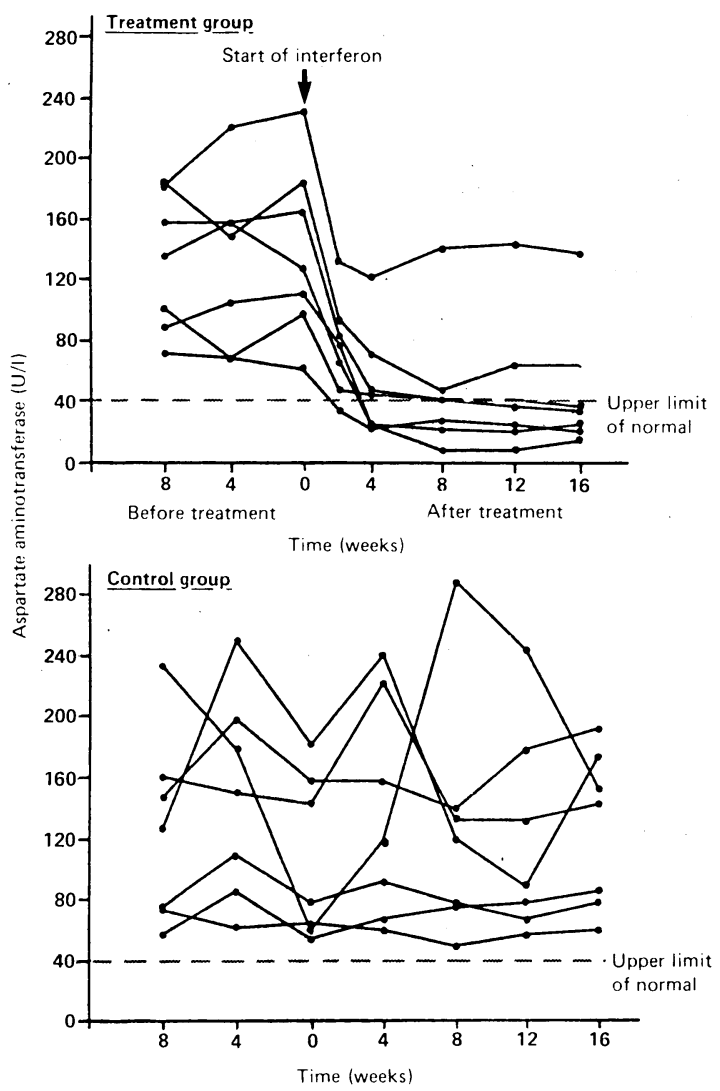

Serum aspartate aminotransferase activities (U/l) over time in treated and control patients with chronic non- $A$ non- $B$ hepatitis

\section{Discussion}

This is the first controlled study to show that interferon alfa can rapidly return aspartate aminotransferase activity to normal in most patients with chronic non-A non-B hepatitis. It confirms the earlier results of pilot studies. ${ }^{56}$ Though all treated patients showed a reduction in aspartate aminotransferase activities, in two patients values did not return to normal. Failure of some patients with chronic non-A non-B hepatitis to respond to interferon was also noted in one of the earlier studies. ${ }^{5}$ Whether this failure of treatment is related to the type of non-A non-B agent (there is probably more than one), misdiagnosis of chronic non-A non-B hepatitis, or individual differences in response to interferon is not known.

Lymphoblastoid interferon alfa is a mixture of $\alpha$ interferons produced by stimulation of a human cell line with Sendai virus. $\alpha$ Interferon has many biological effects, including the induction of intracellular antiviral mechanisms and amplification of the immune response. ${ }^{89}$ Preliminary data indicate that both interferon alfa and recombinant $\alpha$ interferons are effective in some patients with chronic hepatitis B infection. ${ }^{4}$ It has also been shown that $\alpha$ interferon inhibits the replication of hepatitis $\mathrm{A}^{10}$ and hepatitis delta agents. ${ }^{11}$ In some patients with chronic hepatitis $B$ infection interferon precipitates a hepatic illness some weeks after treatment has been started, which probably reflects immune mediated clearance of infected hepatocytes. ${ }^{12}$ By contrast, our results indicate that in chronic non-A non-B infection interferon produces a rapid fall in aspartate aminotransferase activity immediately after starting treatment. This suggests that unlike hepatitis $A$ and $B$ viruses, which cause hepatocyte damage indirectly by immune mediated mechanisms, ${ }^{13}{ }^{14}$ the non- $A$ non- $B$ agent is probably directly hepatocytopathic.

The one patient who developed HIV antibodies shortly after beginning interferon responded within four weeks of starting treatment and continued to have normal aspartate aminotransferase activity during treatment. This is in contrast with chronic hepatitis B infection, in which interferon appears to work less well supports the contention that, whereas in chronic if patients are positive for HIV antibody. ${ }^{8}$ This further 
hepatitis $\mathrm{B}$ infection interferon probably exerts its beneficial effect through the immune system, in chronic non-A non- $B$ infection the interferon acts directly on the virus infected hepatocytes.

These initial results are encouraging, and longer term study of these patients is being undertaken to see whether the histological picture of the liver improves in parallel to biochemical values and also whether the improvement persists after interferon has been discontinued. Preliminary studies suggest that, certainly in some patients, one year of continuous treatment may be successful in bringing about a permanent biochemical and histoiogical remission. Even if relapse does occur on stopping treatment, continuous low dose interferon, which is accompanied by comparatively minor side effects, may be an acceptable inconvenience in view of the high risk of cirrhosis that untreated patients run.

We thank Sister Mary Crossey for help in managing the treatment, Jane Wadsworth for expert statistical advice, and Wellcome Research Laboratories for supplying Wellferon.

\footnotetext{
1 Realdi G, Alberti A, Rugge M. Long-term follow up of acute and chronic non-A non-B hepatitis: evidence of progression to liver cirrhosis. Gut non-A non-B

2 Pappas SC, Hoofnagle JH, Young N, Straus SE, Jones EA. Treatment of
}

non-A non-B hepatitis with acyclovir: a pilot study. 7 Med Virol 1985;15: $1-9$.

3 Hoofnagle JH. Chronic hepatitis. The role of corticosteroids. In: Szmuness W, Alter HJ, Maynard JE, eds. Viral hepatitis - 1981 symposium. Philadelphia: Franklin Institute Press, 1982:573.

4 Thomas HC, Scully LJ. Anti-viral therapy in chronic hepatitis B infection. Br Med Bull 1985;41:374-86.

5 Hoofnagle JH, Muller KD, Jones B, et al. Treatment of chronic non-A non-B hepatitis with recombinant human alpha-interferon. $N$ Engl f Med 1986 315:1575-8.

6 Thompson B, Doran M, Lever AMI, Webster ADB. Alpha-interferon therapy or non-A non-B hepatitis transmitted by gammaglobulin replacemen therapy. Lancet 1987 ; i: $539-41$.

7 Dienstag JL. Non-A non-B hepatitis. I. Recognition, epidemiology and clinical features. Gastroenterology 1983;85:439-62.

$8 \mathrm{McDonald}$ JA, Caruso L, Karayiannis $\mathrm{P}$, et al. Diminished responsiveness of male homosexual chronic hepatitis B carriers with HTLV-III antibodies to male homosexual chronic hepatitis B carriers with HTLV

9 Pignatelli M, Waters J, Brown D, Thomas HC. HLA class I antigen on the hepatocyte membrane during recovery from acute hepatitis $B$ virus infection hepatocyte membrane during recovery from acute hepatitis B virus infection
and during interferon therapy in chronic hepatitis B infection. Hepatology 1986;6:341-53.

10 Vallbracht A, Flehmig B. Elimination of a persistent hepatitis A infection in cell cultures by interferon. In: Kirchner $\mathrm{H}$, Schellekens $\mathrm{H}$, eds. The biology of the interferon system 1984. New York: Elsevier, 1985:339-45.

11 Hoofnagle JH, Smedlie A, Mullen KD, et al. Treatment of chronic delta hepatitis with recombinant human alpha-interferon [Abstract]. Gastroenterology 1985;88:1665.

12 Lever AML, Thomas HC. Treatment of chronic hepatitis B infection. Clinics in Tropical Medicine and Community Diseases 1986;1:377-93.

13 Vallbracht A, Gabriel P, Maier K, et al. Cell-mediated cytotoxicity in hepatitis A virus infection. Hepatology 1986;6:1308-14.

14 Dienstag JL, Bhan AK, Klingenstein RJ, Savarese AM. Immunopathogenesis of tiver disease associated with hepatitis B. In: Szmuness W, Alter HJ, Maynard JE, eds. l'iral hepatitis-1981 symposium. Philadelphia: Franklin Maynard JE, eds. I tral hepaitis

(Accepted 28 October 1988)

\section{Department of \\ Gastroenterology, Hadassah University \\ Hospital, Jerusalem, Israel D Rachmilewitz, MD, professor of medicine and head of department}

The investigators making up the international study group are listed at the end of this paper.

\title{
Coated mesalazine (5-aminosalicylic acid) versus sulphasalazine in the treatment of active ulcerative colitis: a randomised trial
}

\author{
D Rachmilewitz on behalf of an international study group
}

\section{Abstract}

Objective-To assess the safety and efficacy of a preparation of mesalazine (5-aminosalicylic acid) coated with a $\mathrm{pH}$ dependent resin (Eudragit $\mathrm{L}$ ) as compared with sulphasalazine in patients with active mild to moderate ulcerative colitis.

Design-Eight week randomised double blind parallel group study.

Setting-Forty six gastroenterology outpatient clinics in seven countries.

Patients - Two hundred and twenty patients aged 18-70 who met the following criteria: clinical activity index $\geqslant 6$ and endoscopic index $\geqslant 4$; no concomitant treatment for ulcerative colitis; no hypersensitivity to salicylates or sulphonamides. Of the 164 patients eligible for efficacy analysis, 87 received the coated preparation of mesalazine and 77 sulphasalazine. Most of the remaining patients (28 in each group) were ineligible for the efficacy analysis because of treatment with steroid enemas. All pretrial characteristics were comparable in the two treatment groups.

Interventions-Coated mesalazine (Mesasal) $1.5 \mathrm{~g}$ daily or sulphasalazine $3.0 \mathrm{~g}$ daily for eight weeks. Compliance monitored by pill counts.

End point-Clinical and endoscopic remission.

Measurements and main results-Clinical activity measured by daily diary cards, assessment by investigators, and laboratory findings. Endoscopic evaluation at week 8. After four weeks 50 of 70 patients $(71 \%)$ taking coated mesalazine and 38 of 58 $(66 \%)$ taking sulphasalazine had achieved remission of their disease by eight weeks remission rates were $74 \%(37 / 50$ patients) and $81 \%(35 / 43)$ in the two treatment groups respectively. Endoscopic remission at eight weeks was recorded in 20 of 41 patients
$(49 \%)$ taking coated mesalazine and 18 of $38(47 \%)$ taking sulphasalazine. There was a higher incidence of adverse events among patients taking sulphasalazine $(25 / 105 ; 24 \%)$ than among those taking coated mesalazine $(16 / 115 ; 14 \%)$.

Conclusion-Mesalazine coated with Eudragit L is a safe, logical alternative to sulphasalazine.

\section{Introduction}

Sulphasalazine has been a standard treatment for acute inflammatory bowel disease and for maintaining remission since $S$ vartz discovered its anti-inflammatory properties in the 1940s. ${ }^{1-3}$ Its use, however, is limited by intolerance or hypersensitivity in up to one third of patients with the disease..$^{4-6}$ Sulphasalazine is composed of 5-aminosalicylic acid and sulphapyridine joined by an azo bond. 5-Aminosalicylic acid (mesalazine) is the active moiety responsible for the therapeutic efficacy of the drug in ulcerative colitis, ${ }^{7 \cdot 10}$ the sulphapyridine component (acting only as the vehicle for 5-aminosalicylic acid) evidently being responsible for most adverse effects. ${ }^{11-20}$

Though the exact mechanism of action is not clearly established, the anti-inflammatory properties of 5aminosalicylic acid are apparently related to its topical effects on the inflamed colonic mucosa. ${ }^{7}$ Inhibition of several mediators that may have a role in the pathogenesis of the inflammatory response might in part explain the therapeutic effects of 5-aminosalicylic acid. 5-Aminosalicylic acid inhibits the colonic formation of prostanoids, ${ }^{21}$ leucotriene $\mathrm{B}_{4},{ }^{22}$ leucotriene $\mathrm{C}_{4},{ }^{23}$ and platelet activating factor. ${ }^{24}$

To maximise efficacy and minimise toxicity the logical therapeutic approach is delivery of 5-aminosalicylic acid devoid of sulphapyridine to the diseased 